\title{
Nutritional versus behavioural intervention in children with avoidant/restrictive food intake disorder
}

\author{
Porównanie interwencji żywieniowej z interwencją behawioralną u dzieci \\ z zaburzeniem polegającym na ograniczeniu/unikaniu przyjmowania pokarmów
}

\author{
1 Department of Paediatrics, Medical University of Warsaw, Warsaw, Poland \\ ${ }^{2}$ Faculty of Psychology, SWPS University of Social Sciences and Humanities, Warsaw, Poland \\ Correspondence: Katarzyna Bąbik, Faculty of Psychology, SWPS University of Social Sciences and Humanities, Chodakowska 19/31, 03-815 Warsaw, Poland, \\ e-mail: kbabik@swps.edu.pl, ORCID ID:0000-0002-8469-2440
}

\begin{abstract}
Objective: The aim of the study was to determine the effectiveness of nutritional intervention compared to behavioural intervention to increase food acceptance and improve the nutritional status among children with avoidant/restrictive food intake disorder. Method: Six participants (3-4 years old) diagnosed with avoidant/restrictive food intake disorder took part in the study. They were randomly assigned to one of the two interventions, either a nutritional or behavioural approach. Results: The percentage of food acceptance increased for patients in the behavioural intervention group, but not for the nutritional intervention group (until later implementation of behavioural intervention). Moreover, the z-score for body mass index increased only after implementing behavioural intervention. The total score on the Montreal Children's Hospital Feeding Scale decreased only after implementation of intervention based on behavioural approach. Inappropriate mealtime behaviour decreased across all participants after implementation of behavioural intervention. Discussion: Behavioural intervention seems to be promising for children with avoidant/restrictive food intake disorder to increase the oral intake of solid food and improve their growth.
\end{abstract}

Keywords: feeding difficulties, feeding problems, feeding disorders, avoidant/restrictive food intake disorder, behavioural intervention, nutritional intervention

Streszczenie Cel: Celem badania była ocena efektywności interwencji żywieniowej w porównaniu z interwencją behawioralną w zwiększeniu akceptacji doustnej pokarmów oraz poprawie stanu odżywienia u dzieci z zaburzeniem polegającym na ograniczeniu/unikaniu przyjmowania pokarmów (avoidant/restrictive food intake disorder, ARFID). Metoda: W badaniu wzięło udział sześcioro dzieci w wieku 3-4 lata. Wszystkie dzieci miały postawianą diagnozę ARFID. W sposób losowy zostały one przypisane do jednej z dwóch możliwych interwencji - żywieniowej lub behawioralnej. Wyniki: Akceptacja doustna pokarmu wzrosła u dzieci, które otrzymywały interwencję behawioralną. Nie zaobserwowano natomiast takiej zależności u dzieci otrzymujących interwencję żywieniową (do momentu późniejszego wdrożenia interwencji behawioralnej). Dodatkowo z-score dla indeksu masy ciała wzrósł jedynie po wprowadzeniu interwencji behawioralnej. Wynik całkowity w Montreal Children’s Hospital Feeding Scale spadł jedynie po wdrożeniu interwencji behawioralnej. Liczba niewłaściwych zachowań podczas posiłków spadła u wszystkich dzieci, które otrzymały interwencję behawioralną. Omówienie: Wydaje się, że interwencja behawioralna jako główna metoda pracy z dziećmi z ARFID jest obiecującym oddziaływaniem, które zwiększa akceptację pokarmów drogą doustną oraz poprawia stan odżywienia.

Słowa kluczowe: trudności związane z karmieniem, problemy z karmieniem, zaburzenia karmienia, zaburzenie polegające na ograniczeniu/unikaniu przyjmowania pokarmów, interwencja behawioralna, interwencja żywieniowa 


\section{INTRODUCTION}

$\mathrm{I}$ $\mathrm{t}$ is estimated that between 25 and $45 \%$ of all children experience some feeding difficulties in their life (Bentovim, 1970; Kerzner et al., 2015). Feeding difficulties is an umbrella term encompassing all feeding problems, regardless of aetiology or severity (Kerzner et al., 2015; Linscheid, 2006; Williams et al., 2009). They can manifest as partial or total food refusal in the form of tantrums and inappropriate mealtime behaviours (IMB) (Borrero et al., 2010; Luiselli, 2000; Munk and Repp, 1994). Prolonged feeding difficulties may lead to avoidant/restrictive food intake disorder, known also as ARFID (American Psychiatric Association, 2013; World Health Organization, 2018a). ARFID is tied to feeding disorders and it is a replacement diagnosis of "feeding disorder of infancy or early childhood" defined in Diagnostic and Statistical Manual of Mental Disorders DSM-IV (Sharp and Stubbs, 2019). It often manifests itself in a form of significant weight loss, significant nutritional deficiency, dependence on enteral feeding or oral nutritional supplements, and interferes with psychosocial functioning (American Psychiatric Association, 2013; Attia et al., 2013). ARFID might negatively impact a child's health, including susceptibility to infectious diseases, worse cognitive development and emotional regulation (Bryant-Waugh et al., 2010; Budd et al., 1992; Kedesdy and Budd, 1998; de Moor et al., 2007; Silverman and Tarbell, 2009; Sisson and Van Hasselt, 1989). Patients diagnosed with ARFID are also at higher risk for amenorrhea, bradycardia, prolonged QT intervals on electrocardiograms, and electrolyte abnormalities (Nakai et al., 2017; Strandjord et al., 2015; Thomas et al., 2017). Some studies highlight the importance of a well-balanced diet and good nutritional status in children under 5 years of age as it is a critical period for brain development (Nyaradi et al., 2013; Rosales et al., 2009).

After exclusion of potential organic causes of identified feeding problems, the persistence and severity of ARFID can be explained by environmental factors (Cooper et al., 1995; Didden et al., 1999). Caregivers often try various strategies to overcome child's feeding/eating problems. Unfortunately, some of those approaches only reinforce such problems. A child might engage in inappropriate behaviours to terminate the mealtime, or to get access to tangibles (highly preferred activities, items, or attention). If the child is successful, the incidence of problematic behaviours might increase even more in the future (Cooper et al., 1995; Didden et al., 1999; Piazza et al., 2003).

There is a vast amount of literature on interventions designed to increase diet variety and the volume of consumed solids (Sharp and Stubbs, 2019). However, there are not many studies evaluating the efficiency of ARFID treatment (Norris et al., 2016), especially studies that focus on improving nutritional status. According to studies on feeding disorders, it seems that the most beneficial treatment for patients with ARFID would be an intensive multidisciplinary intervention involving multiple specialists; such as a paediatrician, psychologist, behaviour analysts, speechlanguage pathologist, and nutritionists (Norris et al., 2016; Sharp and Stubbs, 2019).

Behavioural approach is one of the most effective psychological interventions for feeding difficulties, including feeding disorders (Hoch et al., 1994; Kerwin, 1999; Lukens and Silverman, 2014; Sharp et al., 2017). Although published literature highlights the importance of nutritional intervention, as one of the main components during treatment, data on its effectiveness is missing (Barnhill et al., 2016). Available studies indicate that nutritional interventions were mostly focused on energy needs, monitoring hydration, and tracking progress in oral intake to adjust tube feeds (Cornwell et al., 2010; Kindermann et al., 2008; Sharp et al., 2017).

The aim of this study was to compare the effectiveness of nutritional intervention vs. behavioural intervention among children diagnosed with ARFID to increase food acceptance, reduce IMB and improve nutritional status. Additionally, a comparison of changes in the total Montreal Children's Hospital Feeding Scale (MCH-FS) score was performed among the participants before and after each intervention.

\section{METHODS}

\section{Ethical approval}

The study was approved by the Ethics Committee of the Medical University of Warsaw (KB/153/2019).

\section{Participants}

The study participants were children who met the following inclusion criteria: (a) were between 2 and 5 years old; (b) had diagnosed ARFID; (c) had insufficient daily calorie intake ( $80 \%$ or less); (d) consumed less than 15 different foods, but at least 3; (e) had an oral feeding history; (f) were self-feeders; ( $g$ ) had excluded organic factors of feeding problems; and (h) were considered as "safe" oral feeders. ARFID was diagnosed by an interdisciplinary team using the diagnostic criteria included in the Diagnostic and Statistical Manual of Mental Disorders $5^{\text {th }}$ ed. (American Psychiatric Association, 2013). Each participant was medically evaluated and had basic laboratory tests done prior to the study. Child's safety during mealtime was assessed by a paediatrician and speech therapist. Food texture was selected according to the child's oral eating history and skills, which were assessed by a speech therapist. The nutritional deficiency diagnosis was based on 3-day food intake records and laboratory findings. Children's diets were analysed by a registered dietician. Exclusion criteria included (a) exclusive breast-feeding, (b) 100\% nasogastric tube (NG-tube) or gastrostomy tube (G-tube) dependence, (c) chronic conditions preventing proper enteral feeding (e.g. genetic or severe neurological disorders), (d) no oral feeding history, (e) ongoing feeding-related intervention, (f) anatomical 
factors causing feeding difficulties, $(\mathrm{g})$ medical indications for specific diet, (h) body mass index (BMI) $\geq+2$ standard deviation $(S D)$ (z-score) and $\leq-2 S D$ (z-score).

Six typically developing children ( 3 boys and 3 girls) between the ages of 3 and 4 years, referred to the clinic for an initial assessment and intervention for feeding problems, were recruited. The clinic had an interdisciplinary team a paediatrician, a gastroenterologist, a nurse, a dietitian, a behaviour analyst and a speech therapist. All participants were monitored by their physician. For detailed description of participants see Appendix 1.

All recruited participants met the diagnostic criteria of ARFID, and medical conditions causing their feeding difficulties were excluded. Sessions were conducted twice a day during one week. The study was conducted at the Department of Paediatrics, Medical University of Warsaw. Written informed consent to participate in the study was obtained from all participants' caregivers. All participants' names were changed to protect their confidentiality.

\section{Setting and materials}

Feeding sessions were conducted in a $3 \times 3 \mathrm{~m}$ room located in a paediatric unit. The children were seated in age-appropriate seats (high-chair or chair), upright in a 90-90-90 position. Other materials included a pencil, paper datasheet, paper towels, timer, gloves, clickers, and a scale. Eating utensils included spoons, forks and plastic bowls or plates.

\section{Dependent variables, response measurement, and reliability}

A trained observer was collecting data on the frequency of bite acceptance and IMB on a trial-by-trial basis using a paper-pencil data sheet. Acceptance was measured by counting how often the child used a utensil or their fingers to put the entire bite of food into their mouth within $10 \mathrm{~s}$ of presentation. The count was then converted to a percentage by dividing the number of bites accepted by the number of bites presented. Bite presentation was understood as placement of a bite-sized amount of food on the spoon/fork in a plate in front of the child (single bite presentation) with a verbal prompt: "take a bite." Inappropriate mealtime behaviours were scored each time the child moved the spoon or bite of food away from their mouth, threw the spoon/plate or the bite, hit the spoon against a surface, covered their mouth, turned their head or moved their torso 45 degrees away from the spoon or bite while the spoon or bite was within 2 inches from the child's mouth. Data on IMB was converted to responses per minute by dividing the total number of IMB in the session by the total length of the time that the behaviours could have occurred. Expels were scored each time when food larger than the size of a pea was still in the mouth, not swallowed $30 \mathrm{~s}$ after being deposited into the child's mouth. Mouth clean was scored when there was no food larger than a pea in the child's mouth $30 \mathrm{~s}$ after the entire bite entered the mouth (excluding the absence of food in the mouth as a result of expulsion). Observers scored mouth clean once for each bite that entered the child's mouth. Mouth clean was converted to a percentage after dividing the number of mouth cleans by the number of bites entering the child's mouth. Bites that entered the mouth during re-presentation were not counted as a mouth clean. Consumed grams was also recorded by observers. Each bowl/plate was placed on a scale before and after mealtime and the weight was recorded on a food log. Grams consumed were calculated as pre post weight of food bowls/plates, adjusted by the weight of paper towels/bib with spill/emesis minus paper towels/bib without spill/emesis (available upon request). Session duration was measured with a timer.

Interobserver agreement (IOA) was assessed for the dependent variables by having two observers independently

\section{Participant description}

Josh was a 42-month-old Caucasian, typically developing boy diagnosed with ARFID. Upon admission, he was consuming 2-3 bottles of high-caloric drinks (NutriKid ${ }^{\circledR}$ ) per day, small amounts of baby cereal, fruit puree, vanilla-flavoured homogenised cheese (Rolmlec ${ }^{\odot}$ ), and rice waffles. He did not receive any therapies regarding his feeding problems prior to admission. Due to reported difficulties with higher textures (gagging), and recommendation of the speech therapist, a level spoon of junior texture food was selected for sessions.

Jessica was a 46-month-old Caucasian, typically developing girl diagnosed with ARFID. She consumed 1 bottle daily of NutriKid ${ }^{\oplus}$ or Fresubin ${ }^{\circledR}$, dry cornflakes, dry bread, plain pancakes, rice waffles, crackers, croissants, and vanilla-flavoured homogenised cheese (Rolmlecz ${ }^{\oplus}$ ). She had speech and occupational therapies prior to admission. Due to history of eating higher texture foods and no safety concerns, a naturally low texture foods (ex. yogurt) and $1 \times 1$ inch bites of regular texture foods were selected for sessions.

Sam was a 37-month-old Caucasian, typically developing boy diagnosed with ARFID. He consumed small volume of chosen stage 1 baby foods. Due to his history of eating only lower textures foods, naturally low texture foods (ex. yogurt) and a level spoon of puree foods were selected for sessions.

Molly was a 39-month-old Caucasian, typically developing girl diagnosed with ARFID. Upon admission to the feeding program, she consumed small volumes of natural yogurt, two flavours of baby rice cereal (vanilla and chocolate) and vanilla-flavoured homogenised cheese (Rolmlecz ${ }^{\odot}$ ). She had speech therapy prior to admission. Due to a history of eating pureed foods, and recommendation of the speech therapist, naturally low texture foods (e.g. yogurt) and a level spoon of junior texture foods were selected for sessions.

Sally was a 44-month-old Caucasian, typically developing girl diagnosed with ARFID. Upon admission to the feeding program, she consumed instant oatmeal (vanilla and banana flavour), French fries, toast with cheese, French toast, plain pancakes, and milk chocolate. She had speech and occupational therapies prior to admission. Due to a history of eating higher textures foods and no safety concerns, a naturally low texture foods (e.g. yogurt) and $1 \times 1$ inch bites of regular texture foods were selected for sessions.

Nick was a 43-month-old Caucasian, typically developing boy diagnosed with ARFID. Upon admission to the feeding program, he consumed 1-2 bottles of high-caloric drinks (NutriDrink $^{\circledast}$ or Fresubin ${ }^{\oplus}$ ) per day, small amounts of toasts with butter, cheese and/or ham, cornflakes, dry bread, instant oatmeal (only vanilla flavour), milk chocolate, pizza crust, vanilla-flavoured homogenised cheese (Rolmlecz ${ }^{\odot}$ ). He had speech therapy prior to admission. Due to a history of eating higher texture foods and no safety concerns, a naturally low texture foods (e.g., yogurt) and $1 \times 1$ inch bites of regular texture foods were selected for sessions.

Appendix 1. Description of participants 


\begin{tabular}{|c|c|}
\hline $\begin{array}{l}\text { Screening visit } \\
\text { (all participants) }\end{array}$ & $\begin{array}{l}\text { - Diagnostic evaluation of feeding difficulties } \\
\text { - Interview assessing the history and current status of feeding, problem behaviour, medical disorders } \\
\text { - Weight and length/height and BMI assessment } \\
\text { - Qualification for research based on inclusion/exclusion criteria } \\
\text { - Child's 3-day food intake record } \\
\text { - Completion of MCH-FS: I measure } \\
\text { - Random assignment to one of two groups: BI or NI }\end{array}$ \\
\hline Appointment with a dietitian - for both groups & $\begin{array}{l}\text { - Appointment with a dietitian } \\
\text { - Quantitative and qualitative assessment of the diet based on a 3-day intake record and dietary interview }\end{array}$ \\
\hline Behavioural intervention & $\begin{array}{l}\text { - } 20 \text { sessions } \\
\text { - Weight and length/height and BMI assessment } \\
\text { - Completion of MCH-FS } \\
\end{array}$ \\
\hline Nutritional intervention & $\begin{array}{l}\text { - } 20 \text { sessions } \\
\text { - Weight and length/height and BMI assessment } \\
\text { - Completion of MCH-FS }\end{array}$ \\
\hline Follow-up; one week after NI/BI & - Weight and length/height and BMl assessment \\
\hline
\end{tabular}

Appendix 2. Research phases

collect data on acceptance and IMB during at least 30\% of sessions of each phase for each participant. IOA was calculated by dividing the smaller of the counts by the larger count and multiplying it by 100 .

Data on intervention integrity was also collected. Intervention integrity was assessed to evaluate the accuracy of implementation of the treatment procedures. Observers scored correct bite presentation, correct praise and incorrect attention. During behavioural intervention, correct bite presentation was scored if any of the following conditions was met: (a) after $10 \mathrm{~s}$ from initial presentation the feeder held the spoon 2 inches in front of the child's lips until acceptance or next bite interval, (b) the feeder followed the child's head with the spoon/fork if the child engaged in any IMB, (c) the feeder re-presented a fresh bite after expulsion or vomiting during session, (d) the feeder presented the spoon with a bite in a plate/bowl within arm's reach of the child $30 \mathrm{~s}$ after previous bite entered the child's mouth and was swallowed, (e) after the child consumed a bite, the feeder removed the plate and spoon/fork. During nutritional intervention, the observer scored correct bite presentation (a) if after $10 \mathrm{~s}$ from the initial presentation

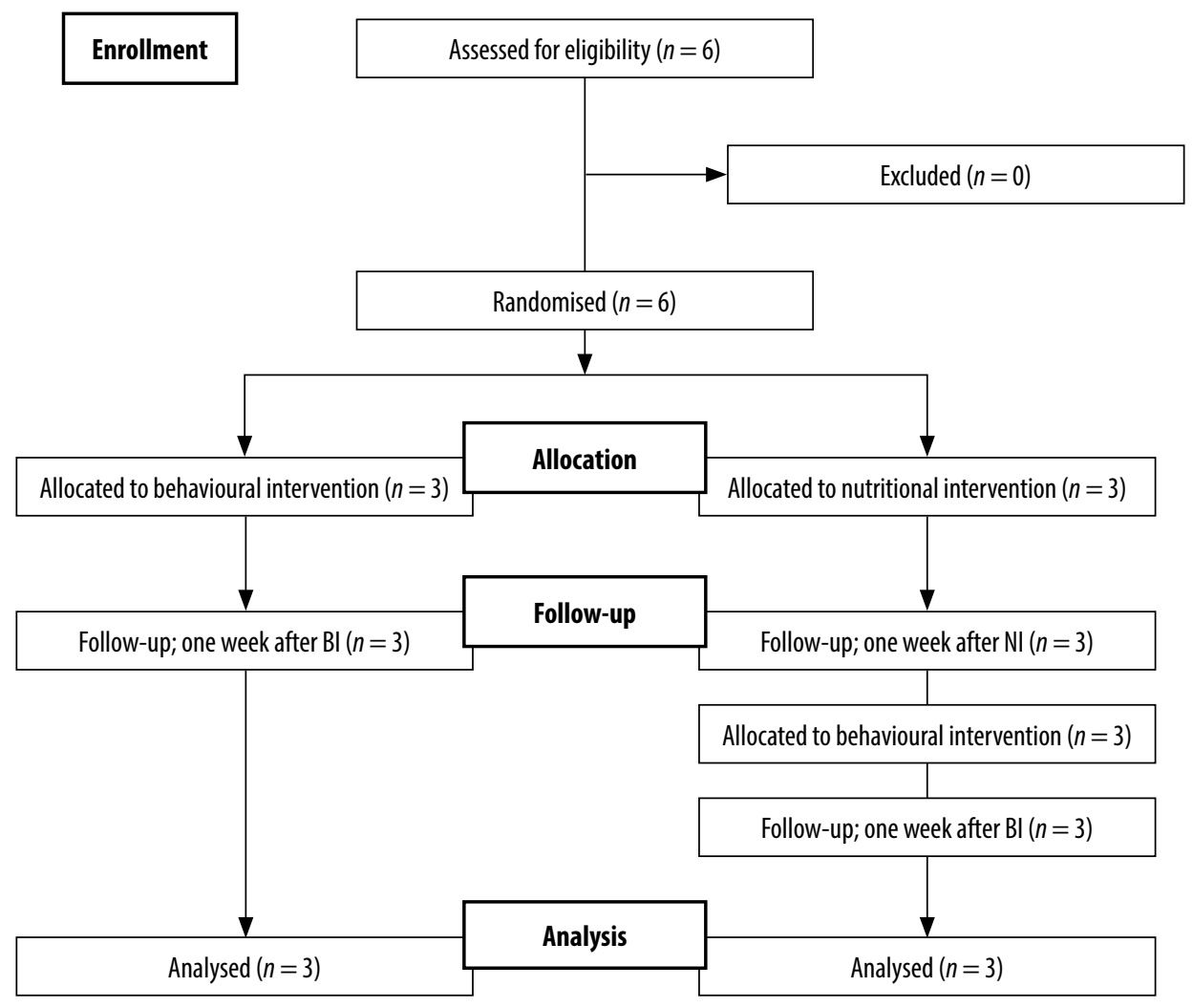


the feeder implemented stationary spoon (the spoon remained stationary) until acceptance or next bite interval, (b) the feeder held the spoon/fork if child engaged in IMB, (c) the feeder presented the spoon with a bite in a plate/ bowl within arm's reach of the child $30 \mathrm{~s}$ after the previous bite entered the child's mouth, (d) after a bite was consumed, the feeder removed the plate and spoon/fork. Observers scored correct praise for behavioural intervention if the therapist provided verbal praise within $5 \mathrm{~s}$ of bite acceptance, when the bites entered the child's mouth before $10 \mathrm{~s}$ and when the child swallowed the bite within $30 \mathrm{~s}$. Incorrect attention was scored for both groups (behavioural and nutritional intervention) when the therapist delivered any form of attention (including eye-contact, physical contact, verbal statements such as reprimands, coaxing) while the child engaged in IMB. The number of correct procedures was divided by the total number of opportunities to implement each component of the meal protocol and multiplied by 100 .

\section{Study design}

A nonconcurrent multiple baseline (NMBL) design across participants assigned to behavioural intervention was used. The design was selected for practical reasons as it was not possible to conduct sessions for participants concurrently. Participants were randomly assigned to a baseline of 3 (Tier 1), 6 (Tier 2) or 9 (Tier 3) sessions. In each tier, baseline sessions were conducted until the specified number of baseline sessions was reached and stable data on acceptance and IMB were obtained. If the food acceptance (ACC) among participants in the nutritional intervention group was lower than $80 \%$, they additionally received behavioural intervention and baseline prior behavioural intervention was conducted (at least 3 sessions with stable data in ACC and IMB).

\section{Sample size calculation}

The primary endpoint was the difference in the level of acceptance between the groups. It was predetermined that an increase in the level of acceptance to at least $80 \%$ and a decrease in IMB to $20 \%$ would be a clinically significant difference. Based on the available data in the applied behaviour analysis studies, three participants per group were recruited in the study (Peterson et al., 2019, 2016).

\section{General procedure}

10-bite sessions were conducted for participants from both groups. The sessions lasted up to 20 minutes. Behavioural and nutritional intervention sessions were scheduled $2 \times$ day per week ( 20 sessions in total). Each participant was offered foods from set 1 during the odd numbered sessions, and foods from set 2 during the others. Three foods were presented to the child in a sequential order during each session. A minimum of 20 sessions per participant in both nutritional intervention and behavioural intervention groups were conducted. If the treatment for a child assigned to behavioural intervention group was effective before session 20 , it was still continued until 20 sessions were completed to make sure that the length and intensity of both interventions were similar.

\section{Randomisation and phases of the research}

The participants were randomly assigned to one of two groups: either behavioural intervention or nutritional intervention group with a 1:1 allocation, using a computer-generated randomisation schedule (StatsDirect). The randomised list was developed and placed by a research assistant in sealed numbered envelopes. Participants assigned to behavioural intervention group: Josh, Jessica, and Sam. Participants assigned to nutritional intervention group: Molly, Sally and Nick. Detailed phases of the research and a flowchart showing the enrolment process are attached as supplementary material (see Appendices 2 and 3).

\section{Assessment of child's nutritional status}

Anthropometric measurements, such as weight and length/ height, were taken for each participant before the study, after behavioural and nutritional intervention, and during follow-up. As recommended by the World Health Organization (WHO), child's weight, length/height and BMI were converted into standard deviation scores (z-scores) to assess growth and nutritional status. The WHO Anthro ( $0-5$ years) software was used for the $\mathrm{z}$-score calculations (World Health Organization, 2018b). The data was interpreted based on WHO Global Database on Child Growth and Malnutrition recommendations (World Health Organization, 2010).

\section{Montreal Children's Hospital Feeding Scale}

MCH-FS was used to verify if the total score, which refers to intensity of feeding difficulties reported by parents, would change before and after receiving interventions. A higher total score on the scale represents more severe symptoms of feeding difficulties. The translated and validated Polish version of the scale was used in the study. The discrimination score for the scale is 46 points (Bąbik et al., 2019).

\section{Nutritionist consultation}

Each participant, regardless of randomly assigned group, had an appointment with a dietitian prior to starting their intervention. Before the appointments, the caregivers were instructed on how to prepare detailed 3-day food intake records. Detailed interviews with caregivers, quantitative and qualitative assessment based on 3-day intake records were conducted. Caregivers received an individualised list of proposed meals for each child. From the received list they chose six target foods (three foods per set) that the child did not eat for at least a month. These sets were used during baseline and treatment sessions. The target foods were oatmeal, applesauce, yogurt (set 1), and carrot, mashed potatoes, chicken 
Non-removal of the spoon, verbal praise for acceptance and swallowing the bite, access to the reinforcement, and visual support

The therapist went with child over the rules: "You will take some bites. If you take your bite I will say: "great job." If you don't take your bite fast enough I will help you. If you take all bites you will earn your ....... (name of the reinforcement)." If the child was taking a bite within $10 \mathrm{~s}$, the therapist provided verbal praise ("Great job!"). If the child did not take a bite within $10 \mathrm{~s}$, the therapist implemented non-removal of the spoon (Sam and Molly: If the child did not take a bite within $10 \mathrm{~s}$ the therapist implemented physical guidance, hand-over-hand, and non-removal of the spoon). The session continued until the child consumed all ten bites or 20 minutes elapsed from the start of the session. Visual items (tokens, blocks) were used to represent the number of bites he/she has to take in order to gain access to the reinforcement. Every time when child accepted and swallowed a bite, the therapist was taking away one of the visual items ( 10 in total). When there were no more items left, the child was getting access to chosen reinforcement. The 1-bite-pack rule was also followed - when the child packed a bite (held a piece of food bigger than a pea size for more than $30 \mathrm{~s}$ in the mouth), the therapist would wait with the presentation of the next bite until all the food was swallowed. Additionally, the therapist checked every $30 \mathrm{~s}$ if the bite was still in the child's mouth. If the child expelled the bite, the therapist immediately re-presented a fresh bite of the same food. There were no programmed consequences for gagging, or coughing.

Appendix 4. Detailed treatment protocol

(set 2) for Josh; sandwich with ham, apple, pancakes (set 1), green bean, rice, chicken (set 2) for Jessica; oatmeal, applesauce, yogurt (set 1), and carrot, mashed potatoes, turkey (set 2) for Sam; oatmeal, applesauce, yogurt (set 1), and broccoli, potatoes, chicken (set 2) for Molly; sandwich with cheese, banana, scramble eggs (set 1), and broccoli, rice, chicken (set 2) for Sally; sandwich with cheese and ham, apple, scrambled eggs (set 1), and corn, rice, chicken for Nick. During each session, foods were served in a rotating sequence. At baseline and during the treatment phase, the foods from set 1 were assigned the odd numbers of the sessions.

Regardless of the group assignment, formula intake was reduced to $50 \%$ for children who were receiving high caloric drinks prior to enrolment to promote and increase oral food intake.

\section{Baseline}

Both interventions (nutritional and behavioural) had the same baseline protocol. The caregiver presented a food bite on a plate in front of the child with a verbal prompt: "take a bite." If the child picked up the spoon within $10 \mathrm{~s}$ and placed the bite in their mouth, the spoon was removed, and another bite was presented within $30 \mathrm{~s}$. If the child failed to pick up the spoon and accept the bite within $10 \mathrm{~s}$ of presentation, the feeder implemented "stationary spoon" until acceptance or $30 \mathrm{~s}$ elapse. After $30 \mathrm{~s}$, the bite was removed and another bite was presented. No programmed consequences were delivered for acceptance, mouth clean, expulsion or IMB. The session was terminated after all 10 bites were consumed or after 20 minutes elapsed.

\section{Nutritional intervention}

Nutritional intervention included nutrition education and general rules to follow outside the scheduled sessions. General rules included (a) 5 mealtimes per day; (b) eating in the kitchen/dining room at the table; (c) keeping at least 3-hour breaks between meals; (d) controlling intake of fluids between scheduled meals; (e) excluding juices and sweet drinks form the diet; (f) excluding snacking (consuming any food between regular main meals); (g) following an individualised meal plan. Caregivers were guided on how to increase calorie intake per meal (ex. by adding a tablespoon of oil to the meal). They were instructed to eat together with their children. During mealtime, the child had access to the food for 20 minutes. After this time, the meal was taken away and the next scheduled meal was served in 3 hours. During the breaks between meals, the child had no access to any other food, but was allowed to drink water. Water intake was controlled and limited especially an hour before the next scheduled meal. Caregivers were also encouraged to involve their child in planning and preparing meals at home. During scheduled sessions, the baseline protocol was followed.

\section{Behavioural intervention}

Free-operant preference assessments (Roane et al., 1998) were conducted with all participants prior to behavioural intervention to identify potential reinforcers. Mealtime protocol included presentation of 10 bites of food per session. The session was terminated when the planned bites were consumed or when 20 minutes passed. Intervention packages for participants were developed based on the functional assessment and history of already implemented intervention components. Intervention package for participants consisted of: non-removal of the spoon (positioning the spoon in front of the child's mouth until the bite is accepted), verbal praise for acceptance and swallowing the bite, access to the reinforcement, and visual support. Visual support was used to represent the number of bites the child had to consume in order to gain access to the reinforcement; if the child accepted and swallowed a bite, the therapist took away one of the visual items; when there were no visual items, then the child was given access to the chosen reinforcer. Additionally, hand-over-hand guidance (when the child did not accept the bite within $10 \mathrm{~s}$ from the initial prompt "take a bite", the feeder used hand-over-hand guidance to prompt the child to position the spoon 2 inches from child's lips) was used for Sam and Molly. The procedures for expulsions, vomiting, gagging, coughing, or IMB were the same for all participants. If a child expelled food, the therapist re-presented the bite immediately. Placement of the bite occurred only if the child opened their mouth at any time, with the exception of coughing, yawning, or vomiting. All of the inappropriate behaviours during mealtime were ignored. Detailed treatment protocol is attached in Appendix 4.

\section{Follow-up}

All participants had follow-up sessions conducted after the predetermined period of 1 week after the intervention had been completed. Three meals were used to assess whether the intervention effects were maintained. Additionally, the MCH-FS was completed and weight and length/height and BMI assessments were conducted. 
BSL

BI

FU

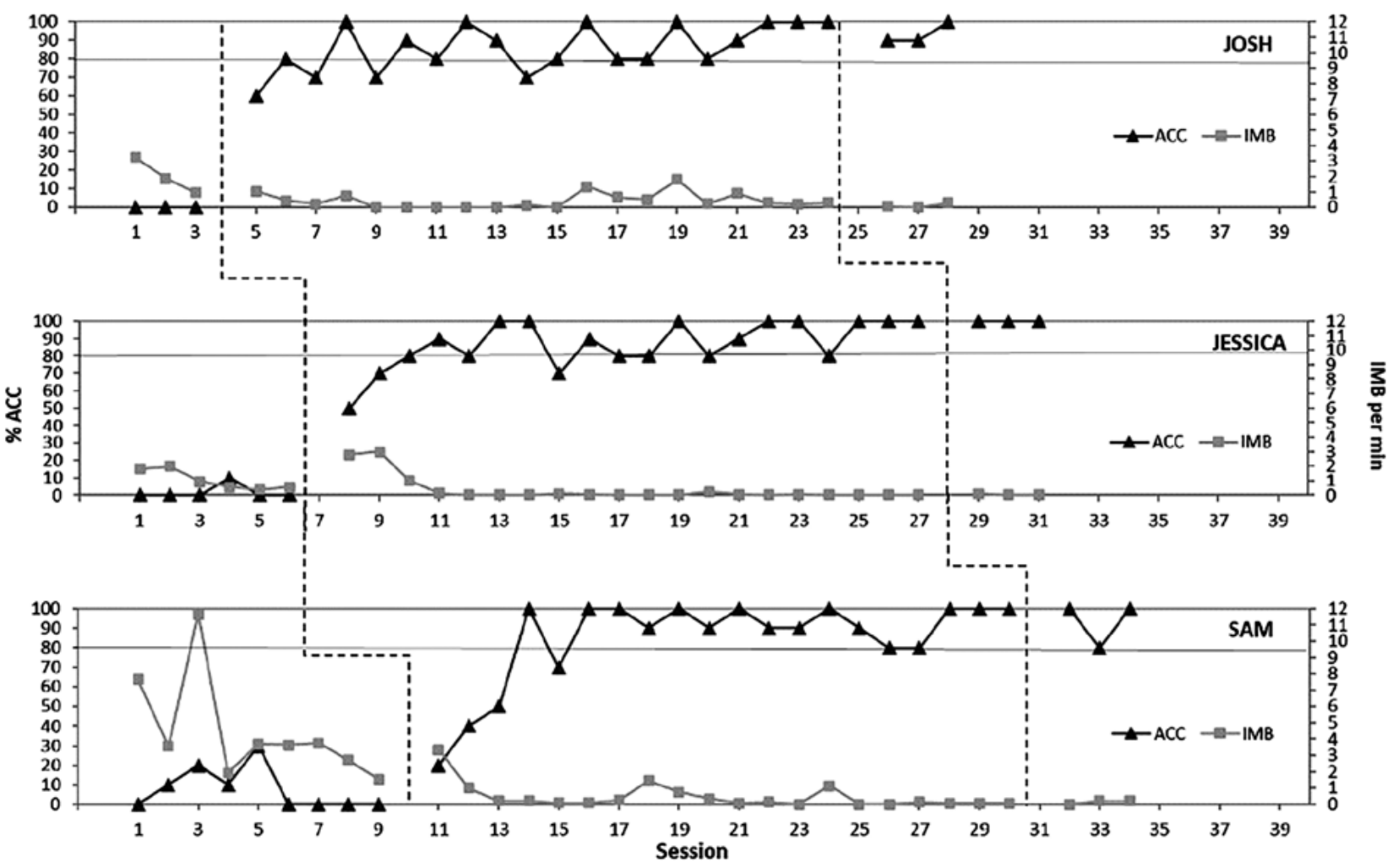

BSL - baseline condition; BI - behavioural intervention; FU - follow-up; ACC - acceptance; IMB - inappropriate mealtime behaviour.

Fig. 1. Percentage of acceptance (\% ACC) and inappropriate mealtime behaviours per minute (IMB per min) for Josh, Jessica and Sam (behavioural intervention group)

\section{Caregiver training}

After the intervention was completed, the caregivers were trained to implement behavioural intervention protocol with $80 \%$ or greater integrity. The training involved written instructions, feedback, modelling and role-play.

\section{Criteria for discontinuing intervention}

Participants could discontinue the intervention at any time at their request.

\section{Interobserver agreement}

Mean interobserver agreement across participants was 98.17\% (range: $81 \%$ to $100 \%$ ) for acceptance, $98.38 \%$ (range: $95 \%$ to $100 \%$ ) for consumed grams and $98.3 \%$ (range: $80 \%$ to $100 \%$ ) for IMB. The independent observer coded data for $50 \%$ of all sessions for Josh, 59\% for Jessica, $62 \%$ for Sam, $43 \%$ for Molly, $44 \%$ for Sally, and 48\% for Nick.

\section{Intervention integrity}

Intervention integrity was calculated for approximately $30 \%$ for all sessions for Josh, Jessica, Molly, Sam, Nick and 45\% for Sally. For all participants, sessions were implemented with $95 \%$ or higher integrity across all sessions.

\section{RESULTS}

\section{Comparison between nutritional and behavioural intervention}

Fig. 1 displays acceptance and IMB for Josh, Jessica and Sam, who were assigned to behavioural intervention group. For Josh, the mean acceptance, grams consumed, and IMB per minute were $0 \%, 0$, and 2.03 (range: 0.95 to 3.25), respectively, across behavioural intervention baseline. Acceptance ( $M=86 \%$; range: $60 \%$ to $100 \%)$, grams consumed 46.90 (range: 35 to 50 ) increased, and IMB per minute $(M=0.44$; range: 0 to 1.8$)$ decreased during behavioural intervention. During the follow-up, the mean acceptance was high at $93.33 \%$ (range: $90 \%$ to $100 \%$ ), grams consumed 49.7 (range: 49 to 50 ) and IMB low at 0.12 (range: 0 to 0.05 ). For Jessica, the mean acceptance, grams consumed, and IMB per minute were $1.67 \%$ (range: $0 \%$ to $10 \%$ ), 0.5 (range: 0 to 2), and 1.04 (range: 0.4 to 2), respectively, across behavioural intervention baseline. Acceptance $(M=87 \%$; range: $50 \%$ to $100 \%$ ) and grams consumed 8.45 (range: 2 to 11$)$ increased, and IMB per minute $(M=0.37$; range: 0 to 2.8 ) decreased during behavioural treatment. During 


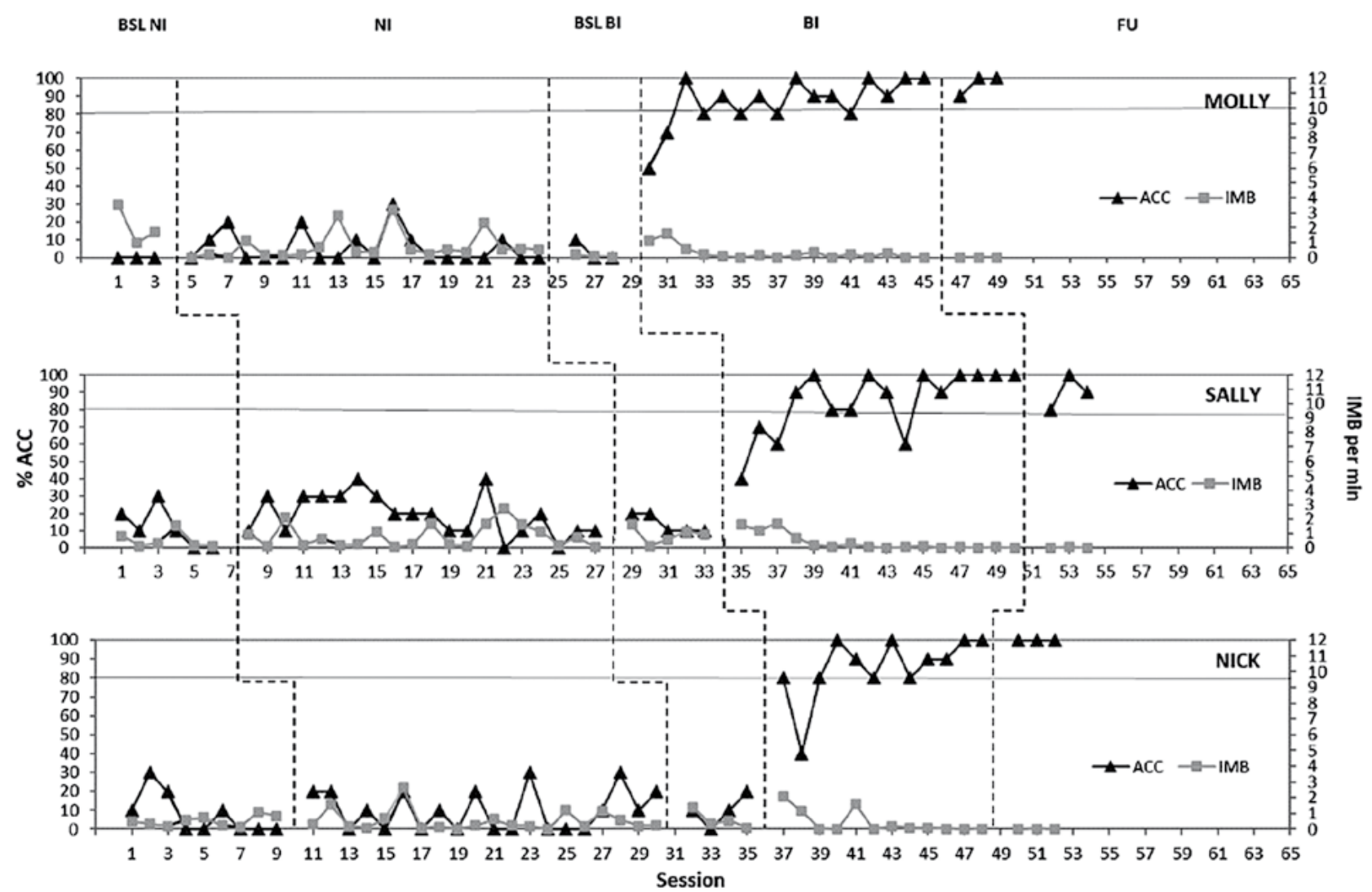

BSL NI - baseline condition before nutritional intervention; $\mathbf{N I}$ - nutritional intervention; BSL BI - baseline condition before behavioural intervention; B - behavioural intervention; FU - follow-up; ACC - acceptance; IMB - inappropriate mealtime behaviour.

Fig. 2. Percentage of acceptance (\% ACC) and inappropriate mealtime behaviours per minute (IMB per min) for Molly, Sally and Nick (nutritional intervention group)

the follow-up, the mean acceptance was high at $100 \%$, grams consumed 9.67 (range: 9 to 10 ) and IMB low at 0.03 (range: 0 to 0.1 ). For Sam, the mean acceptance, grams consumed, and IMB per minute were $7.78 \%$ (range: $0 \%$ to $30 \%$ ), 1 (range: 0 to 5), and 4.46 (range: 1.55 to 11.65 ), respectively, across behavioural intervention baseline. Acceptance ( $M=84.5 \%$; range: $20 \%$ to $100 \%)$, grams consumed 49.3 (range: 47 to 51 ) increased, and IMB per minute ( $M=0.47$; range: 0 to 3.35$)$ decreased during behavioural intervention. During the follow-up, the mean acceptance was high at $93.33 \%$ (range: $80 \%$ to $100 \%$ ), grams consumed 49.67 (range: 49 to 50 ) and IMB low at 0.13 (range: 0 to 0.2 ). Fig. 2 displays acceptance and IMB for Molly, Sally and Nick, who were assigned to the nutritional intervention group. For Molly, the mean acceptance, grams consumed, and IMB per minute were $0 \%, 0$, and 2.08 (range: 0 to 2.8), respectively, across nutritional intervention baseline. Acceptance $(M=5.5 \%$; range: $0 \%$ to $30 \%)$, and grams consumed 2.7 (range: 0 to 1 ) slightly increased, and IMB per minute $(M=0.78$; range: 0 to 3.25$)$ slightly decreased as well during nutritional intervention. Mean acceptance, grams consumed, and IMB per minute were $3.33 \%$ (range: $0 \%$ to $10 \%$ ), 2.25 (range: 0 to 9 ), 0.12 (range: 0.05 to 0.2 ),
Acceptance ( $M=86.88 \%$; range: $50 \%$ to $100 \%)$, and grams consumed 49.81 (range: 47 to 52 ) increased, and IMB per minute ( $M=0.30$; range: 0 to 1.15$)$ decreased during behavioural intervention in comparation to nutritional intervention. During the follow-up, the mean acceptance was high at $96.67 \%$ (range: $90 \%$ to $100 \%$ ), grams consumed 49.33 (range: 48 to 50) and IMB low at 0. For Sally, the mean acceptance, grams consumed, and IMB per minute were $11.67 \%$ (range: $0 \%$ to $30 \%$ ), 2 (range: 0 to 5 ), and 0.54 (range: 0.15 to 1.55 ), respectively, across nutritional intervention baseline. Acceptance $(M=19 \%$; range: $0 \%$ to $40 \%)$, and grams consumed 2.75 (range: 0 to 5 ) slightly increased, and so did the IMB per minute $(M=0.82$; range: 0.05 to 2.1$)$ during nutritional intervention. The mean acceptance, grams consumed, and IMB per minute were $14 \%$ (range: $10 \%$ to $20 \%$ ), 2.2 (range: 1 to 3 ), and 0.89 (range: 0.15 to 1.6), respectively, across behavioural intervention baseline. Acceptance ( $M=85 \%$; range: $40 \%$ to $100 \%)$, and grams consumed 8.75 (range: 5 to 11 ) increased, and IMB per minute $(M=0.39$; range: 0 to 1.7$)$ decreased during behavioural intervention vs. nutritional intervention. During the follow-up, the mean acceptance was high at 90\% (range: $80 \%$ to $100 \%$ ), grams consumed 10 (range: 9 to 11 ) and IMB low at 0.03 (range: 0 to 0.1 ). For Nick, the mean acceptance, 
Josh

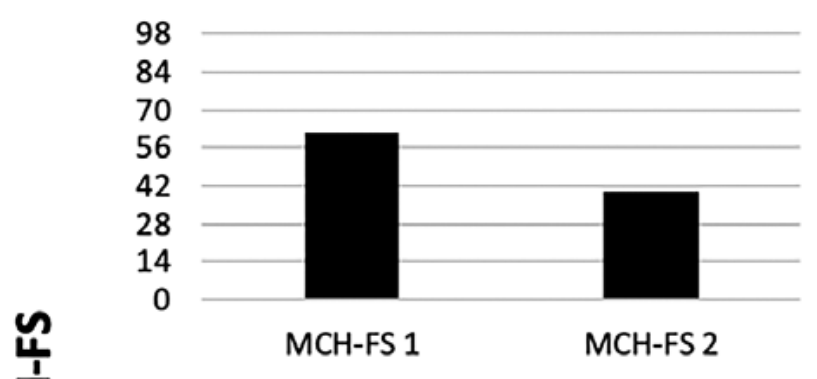

Jessica

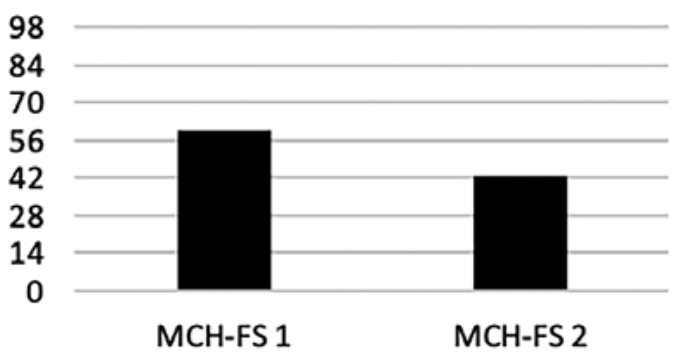

Sam

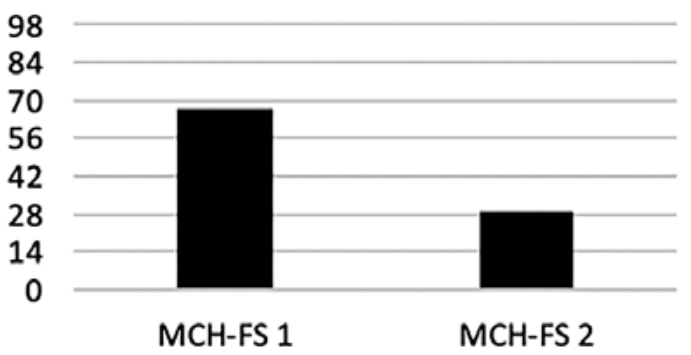

Molly

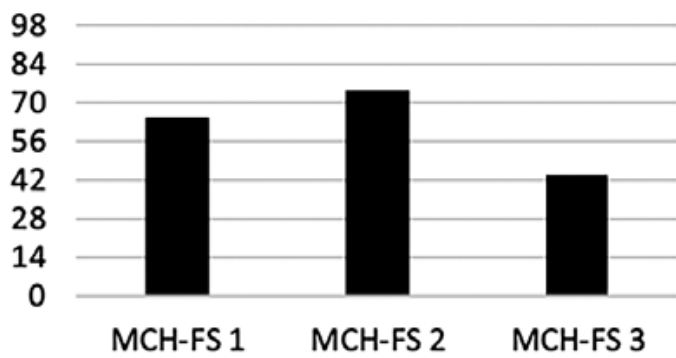

Sally

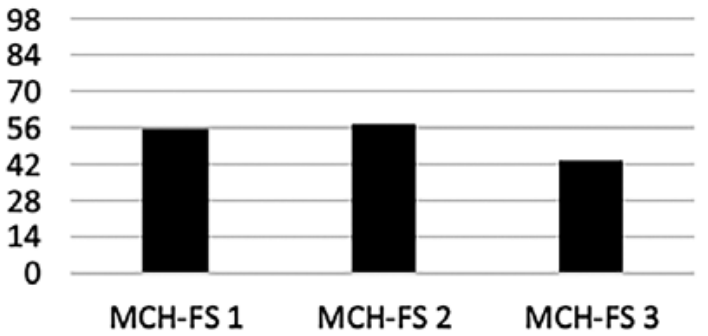

Nick

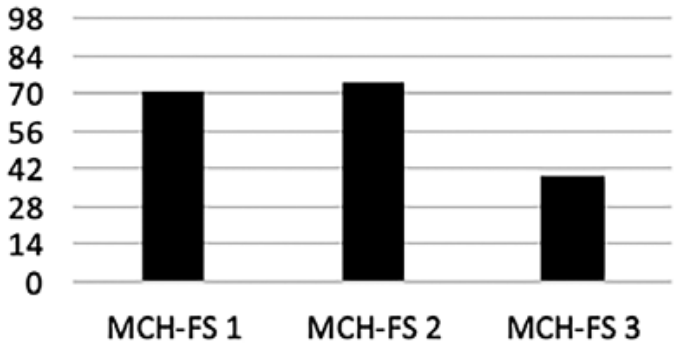

Fig. 2. Percentage of acceptance (\% ACC) and inappropriate mealtime behaviours per minute (IMB per min) for Molly, Sally and Nick (nutritional intervention group)

grams consumed, and IMB per minute were $7.77 \%$ (range: $0 \%$ to $30 \%$ ), 1.11 (range: 0 to 3 ), and 0.53 (range: 0.2 to 1.1 ), respectively, across nutritional intervention baseline. Acceptance ( $M=10 \%$; range: $0 \%$ to $30 \%)$, and grams consumed 1.3 (range: 0 to 4 ) slightly increased, and so did the IMB per minute $(M=0.54$; range: 0 to 2.65$)$ during nutritional intervention. Mean acceptance, grams consumed, and IMB per minute were $10 \%$ (range: $0 \%$ to $20 \%$ ), 2 (range: 1 to 3 ), and 0.6 (range: 0.1 to 1.4 ), respectively, across behavioural intervention baseline. Acceptance ( $M=85.83 \%$; range: $40 \%$ to $100 \%$ ), and grams consumed 9.58 (range: 5 to 13 ) increased, whereas IMB per minute ( $M=0.45$; range: 0 to 2.1 ) decreased during behavioural intervention vs. nutritional intervention. During the follow-up, the mean acceptance was high at $100 \%$, grams consumed 10.33 (range: 9 to 12) and IMB low at 0.02 (range: 0 to 0.05$)$.

\section{Weight and length/height and BMI assessment}

Overall BMI z-score improved only after behavioural intervention. Also, this trend was maintained during the follow-up sessions. BMI z-score was -1.1 at baseline, -1 after behavioural intervention, and -0.85 during follow-up for Josh; 0.49 at baseline, 0.57 after behavioural intervention, and 0.61 during follow-up for Jessica; -0.08 at baseline, -0.07 after behavioural intervention, and 0.12 during follow-up for Sam; -1.1 at first baseline, -1.2 after nutritional intervention, -1 after behavioural intervention, and -0.9 during follow-up for Molly; 0.32 during first baseline, -0.1 after nutritional intervention, 0.01 after behavioural intervention, and 0.14 during follow-up for Sally; -1.07 during first baseline, -1.2 after nutritional intervention, -1.1 after behavioural intervention, and -1 during follow-up for Nick. 


\section{Montreal Children's Hospital Feeding Scale}

The total MCH-FS score decreased after behavioural intervention for all participants. The total MCH-FS score slightly increased for patients after receiving nutritional intervention. This means that caregivers were reporting more symptoms of feeding difficulties in their children during nutritional intervention. The comparison of results is presented in Fig. 3. After behavioural intervention, the total $\mathrm{MCH}-\mathrm{FS}$ score for all participants was below 46 .

\section{DISCUSSION}

The study showed that behavioural intervention was effective to increase acceptance and consumed grams of the foods across all participants diagnosed with ARFID. After behavioural intervention, the participants' body weight increased, contributing to a significant improvement of their nutritional status. Additionally, we observed a decrease in IMB, and caregivers were reporting fewer symptoms of feeding difficulties (which were measured with MCH-FS). The total MCH-FS score for each participant dropped below 46 , which is the cutoff point for the clinical level of feeding difficulties. In other words, after receiving behavioural intervention, the symptoms of feeding difficulties among those children decreased and they no longer met the diagnostic criteria of feeding difficulties. Our results are consistent with Benoit et al. (2000), who reported that nutritional intervention alone is not effective. Benoit et al. (2000) study goal was to eliminate the need for tube feeding. We did not include participants who were fed by nasogastric tube (NG-tube) or gastrostomy tube (G-tube), but only children who were taking high-calory supplements, in our study. We managed to decrease the intake of high calorie drinks by $50 \%$, while improving the weight gain in our participants, but only after behavioural intervention. The nutritional intervention conducted alone did not increase oral intake of solids or weight gain among children diagnosed with ARFID. Moreover, we observed a drop of weight for all participants after implementation of nutritional intervention alone. The nutritional status was assessed after each phase of the study to control each participant's growth parameters. We did not find any studies which would evaluate (in detail) the available interventions and plans for discontinuing a feeding tube while controlling the nutritional status of the child. It would be beneficial for clinicians to conduct such a study in the future.

The current paper is one of the few to assess behavioural intervention in children, conducted as a single case experimental design with randomisation (Peterson et al., 2019, 2016; Sharp et al., 2016). Precise eligibility criteria for the inclusion and exclusion of participants were used. The population enrolled consisted of typically developing children. Due to the lack of trained staff or a possibility to conduct more than one intervention at a time, we chose to use a nonconcurrent multiple baseline design for our study. It controls for some threats to internal validity, such as maturation, test-retest sensitivity, and instrumentation (Harvey et al., 2004). While conducting a comparison study, one of the potential problems using nonconcurrent multiple baseline design might be receiving the same length of the interventions while having stable data in each phase. In our study, we did not face such a problem, although we encourage to use a different design in comparison to studies with small sample size.

Oral acceptance for 10-bites of 6 different foods increased above $80 \%$ during behavioural intervention in all six participants. Further assessments and interventions for our participants will focus on increasing the volume of solids to match their daily calory needs, and introducing new foods to balance their diet. Additionally, we planned a texture assessment and introduction of the age-appropriate food texture for Josh, Sam and Molly.

A small sample size, which might not be enough to generalise the results across all children with ARFID, is a limitation of the study. Additionally, in order to compare two interventions, the nutritional intervention sessions were also structuralised (the same length of sessions, the same number of presented bites, the same size of bites). In the nutritional intervention protocol there were no consequences for IMB. IMB did not terminate the mealtime and the feeder continued with bite presentation until all of the 10-bites were consumed or time of the session elapsed. Future studies should attempt to develop a protocol for nutritional intervention where implementation of specific recommendations are possible to be monitor by the therapist. Another potential limitation of the study might be the comparison of consumed grams across different textures. A bite of regular texture food, spoon of naturally lower texture or level-spoon of junior texture food varied in weight. Therefore, we recommend to either use only the same texture solids or use calorie count to estimate the calory intake in the future. We also recommend to assess the feeding skills of the recruited participants. In our study, we had to add additional physical guidance (hand-over-hand) in Sam and Molly's protocol since their self-feeding skills still required feeder's support. Future studies should also focus on evaluating effective treatment for teenagers and adults diagnosed with ARFID. Dumont et al. (2019) showed promising results of exposure-based cognitive behavioural therapy for adolescents with ARFID in their study. Future studies could also compare effectiveness and social validity of behavioural intervention with cognitive behavioural therapy interventions in this population.

\section{CONCLUSIONS}

Our findings suggest that a behavioural intervention is an effective approach for improving feeding behaviour and nutritional status of children diagnosed with ARFID, while a nutritional intervention alone is insufficient. 


\section{Conflict of interest}

The authors declare no conflict of interest.

\section{Funding/Support and role of the sponsor}

The authors received no financial support for this project.

\section{Acknowledgments}

We would like to thank the participants and their families for their involvement in this study.

\section{Ethical approval}

All procedures performed in studies involving human participants were in accordance with the ethical standards of the institutional and/or national research committee and with the 1964 Helsinki Declaration and its later amendments or comparable ethical standards.

\section{Informed consent}

Informed consent was obtained from each participant included in the study.

\section{Data availability statement}

The data is not publicly available due to ethical restrictions (containing information that could compromise the privacy of research participants).

\section{References}

American Psychiatric Association: Diagnostic and Statistical Manual of Mental Disorders: DSM-5: Fifth Edition. American Psychiatric Association, Arlington, VA 2013.

Attia E, Becker AE, Bryant-Waugh R et al.: Feeding and eating disorders in DSM-5. The Am J Psychiatry 2013; 170: 1237-1239.

Barnhill K, Tami A, Schutte C et al.: Targeted nutritional and behavioral feeding intervention for a child with autism spectrum disorder. Case Rep Psychiatry 2016; 2016: 1420549.

Bąbik K, Dziechciarz P, Horvath A et al.: The Polish version of the Montreal Children's Hospital Feeding Scale (MCH-FS): translation, cross cultural adaptation, and validation. Pediatr Pol 2019; 94: 299-305.

Benoit D, Wang EE, Zlotkin SH: Discontinuation of enterostomy tube feeding by behavioral treatment in early childhood: a randomized controlled trial. J Pediatr 2000; 137: 498-503.

Bentovim A: The clinical approach to feeding disorders of childhood. J Psychosom Res 1970; 14: 267-276.

Borrero CSW, Woods JN, Borrero JC et al.: Descriptive analyses of pediatric food refusal and acceptance. J Appl Behav Anal 2010; 43: 71-88.

Bryant-Waugh R, Markham L, Kreipe RE et al.: Feeding and eating disorders in childhood. Int J Eat Disord 2010; 43: 98-111.

Budd KS, McGraw TE, Farbisz R et al.: Psychosocial concomitants of children's feeding disorders. J Pediatr Psychol 1992; 17: 81-94.

Cooper LJ, Wacker DP, McComas JJ et al.: Use of component analyses to identify active variables in treatment packages for children with feeding disorders. J Appl Behav Anal 1995; 28: 139-153.

Cornwell SL, Kelly K, Austin L: Pediatric feeding disorders: effectiveness of multidisciplinary inpatient treatment of gastrostomy-tube dependent children. Child Health Care 2010; 39: 214-231.

Didden R, Seys D, Schouwink D: Treatment of chronic food refusal in a young developmentally disabled child. Behav Interv 1999; 14: 213-222.

Dumont E, Jansen A, Kroes D et al.: A new cognitive behavior therapy for adolescents with avoidant/restrictive food intake disorder in a day treatment setting: a clinical case series. Int J Eat Disord 2019; 52: 447-458.
Harvey MT, May ME, Kennedy CH: Nonconcurrent multiple baseline designs and the evaluation of educational systems. J Behav Educ 2004; 13: 267-276.

Hoch T, Babbitt RL, Coe DA et al.: Contingency contacting. Combining positive reinforcement and escape extinction procedures to treat persistent food refusal. Behav Modif 1994; 18: 106-128.

Kedesdy JH, Budd KS: Childhood Feeding Disorders: Biobehavioral Assessment and Intervention. Paul H. Brookes Publishing Company, Baltimore, MD 1998

Kerwin ME: Empirically supported treatments in pediatric psychology: severe feeding problems. J Pediatr Psychol 1999; 24: 193-214; discussion 215-196.

Kerzner B, Milano K, MacLean WC Jr et al.: A practical approach to classifying and managing feeding difficulties. Pediatrics 2015; 135 : 344-353.

Kindermann A, Kneepkens CMF, Stok A et al.: Discontinuation of tube feeding in young children by hunger provocation. J Pediatr Gastroenterol Nutr 2008; 47: 87-91.

Linscheid TR: Behavioral treatments for pediatric feeding disorders. Behav Modif 2006; 30: 6-23.

Luiselli JK: Cueing, demand fading, and positive reinforcement to establish self-feeding and oral consumption in a child with chronic food refusal. Behav Modif 2000; 24: 348-358.

Lukens CT, Silverman AH: Systematic review of psychological interventions for pediatric feeding problems. J Pediatr Psychol 2014; 39: 903-917.

de Moor J, Didden R, Korzilius H: Behavioural treatment of severe food refusal in five toddlers with developmental disabilities. Child Care Health Dev 2007; 33: 670-676.

Munk DD, Repp AC: Behavioral assessment of feeding problems of individuals with severe disabilities. J Appl Behav Anal 1994; 27: 241-250.

Nakai Y, Nin K, Noma S et al.: Clinical presentation and outcome of avoidant/restrictive food intake disorder in a Japanese sample. Eat Behav 2017; 24: 49-53.

Norris ML, Spettigue WJ, Katzman DK: Update on eating disorders: current perspectives on avoidant/restrictive food intake disorder in children and youth. Neuropsychiatr Dis Treat 2016; 12: 213-218.

Nyaradi A, Li J, Hickling S et al.: The role of nutrition in children's neurocognitive development, from pregnancy through childhood. Front Hum Neurosci 2013; 7: 97.

Peterson KM, Piazza CC, Ibañez VF et al.: Randomized controlled trial of an applied behavior analytic intervention for food selectivity in children with autism spectrum disorder. J Appl Behav Anal 2019; 52: 895-917.

Peterson KM, Piazza CC, Volkert VM: A comparison of a modified sequential oral sensory approach to an applied behavior-analytic approach in the treatment of food selectivity in children with autism spectrum disorder. J Appl Behav Anal 2016; 49: 485-511.

Piazza CC, Fisher WW, Brown KA et al.: Functional analysis of inappropriate mealtime behaviors. J Appl Behav Anal 2003; 36: 187-204.

Roane HS, Vollmer TR, Ringdahl JE et al.: Evaluation of a brief stimulus preference assessment. J Appl Behav Anal 1998; 31: 605-620.

Rosales FJ, Reznick JS, Zeisel SH: Understanding the role of nutrition in the brain and behavioral development of toddlers and preschool children: identifying and addressing methodological barriers. Nutr Neurosci 2009; 12: 190-202.

Sharp WG, Stubbs KH: Avoidant/restrictive food intake disorder: a diagnosis at the intersection of feeding and eating disorders necessitating subtype differentiation. Int J Eat Disord 2019; 52: 398-401.

Sharp WG, Stubbs KH, Adams H et al.: Intensive, manual-based intervention for pediatric feeding disorders: results from a randomized pilot trial. J Pediatr Gastroenterol Nutr 2016; 62: 658-663.

Sharp WG, Volkert VM, Scahill L et al.: A systematic review and metaanalysis of intensive multidisciplinary intervention for pediatric feeding disorders: how standard is the standard of care? J Pediatr 2017; 181: 116-124.e4.

Silverman AH, Tarbell S: Feeding and vomiting problems in pediatric populations. In: Roberts MC, Steele RG (eds.): Handbook of Pediatric Psychology. $4^{\text {th }}$ ed., The Guilford Press, New York 2009: 429-445. 
Sisson LA, Van Hasselt VB: Feeding disorders. In: Luiselli JK (ed.): Behavioral Medicine and Developmental Disabilities. SpringerVelag, New York 1989: 45-73.

Strandjord SE, Sieke EH, Richmond M et al.: Avoidant/restrictive food intake disorder: illness and hospital course in patients hospitalized for nutritional insufficiency. J Adolesc Health 2015; 57: 673-678.

Thomas JJ, Lawson EA, Micali N et al.: Avoidant/restrictive food intake disorder: a three-dimensional model of neurobiology with implications for etiology and treatment. Curr Psychiatry Rep 2017; 19: 54.

Williams KE, Riegel K, Kerwin ML: Feeding disorder of infancy or early childhood: how often is it seen in feeding programs? Child Health Care 2009; 38: 123-136.
World Health Organization: International Classification of Diseases for Mortality and Morbidity Statistics. Eleventh Revision. World Health Organization, 2018a.

World Health Organization: Nutrition Landscape Information System (NLIS) country profile indicators: interpretation guide. World Health Organization, Geneva 2010.

World Health Organization: WHO Anthro Survey Analyser: Software for analysing survey anthropometric data for children under 5 years of age. Built-in software edition. 1.0 ed. World Health Organization, Geneva 2018b. 